
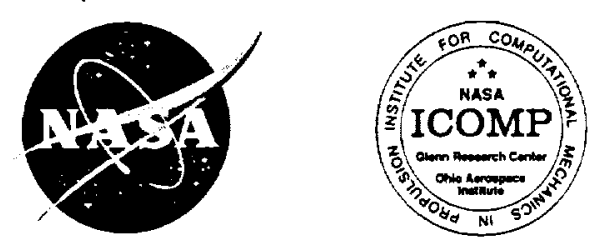

\title{
Bypass Transitional Flow Calculations Using a Navier-Stokes Solver and Two-Equation Models
}

William W. Liou

Western Michigan University, Kalamazoo, Michigan

Tsan-Hsing Shih

Institute for Computational Mechanics in Propulsion, Cleveland, Ohio 
Since its founding, NASA has been dedicated to the advancement of aeronautics and space science. The NASA Scientific and Technical Information (STI) Program Office plays a key part in helping NASA maintain this important role.

The NASA STI Program Office is operated by Langley Research Center, the Lead Center for NASA's scientific and technical information. The NASA STI Program Office provides access to the NASA STI Database, the largest collection of aeronautical and space science STI in the world. The Program Office is also NASA's institutional mechanism for disseminating the results of its research and development activities. These results are published by NASA in the NASA STI Report Series, which includes the following report types:

- TECHNICAL PUBLICATION. Reports of completed research or a major significant phase of research that present the results of NASA programs and include extensive data or theoretical analysis. Includes compilations of significant scientific and technical data and information deemed to be of continuing reference value. NASA's counterpart of peerreviewed formal professional papers but has less stringent limitations on manuscript length and extent of graphic presentations.

- TECHNICAL MEMORANDUM. Scientific and technical findings that are preliminary or of specialized interest, e.g., quick release reports, working papers, and bibliographies that contain minimal annotation. Does not contain extensive analysis.

- CONTRACTOR REPORT. Scientific and technical findings by NASA-sponsored contractors and grantees.
- CONFERENCE PUBLICATION. Collected papers from scientific and technical conferences, symposia, seminars, or other meetings sponsored or cosponsored by NASA.

- SPECIAL PUBLICATION. Scientific, technical, or historical information from NASA programs, projects, and missions, often concerned with subjects having substantial public interest.

- TECHNICAL TRANSLATION. Englishlanguage translations of foreign scientific and technical material pertinent to NASA's mission.

Specialized services that complement the STI Program Office's diverse offerings include creating custom thesauri, building customized data bases, organizing and publishing research results ... even providing videos.

For more information about the NASA STI Program Office, see the following:

- Access the NASA STI Program Home Page at http://www.sti.nasa.gov

- E-mail your question via the Internet to help@sti.nasa.gov

- Fax your question to the NASA Access Help Desk at (301) 621-0134

- Telephone the NASA Access Help Desk at (301) 621-0390

- Write to:

NASA Access Help Desk

NASA Center for AeroSpace Information 7121 Standard Drive

Hanover, MD 21076 
NASA/CR-2000-209923
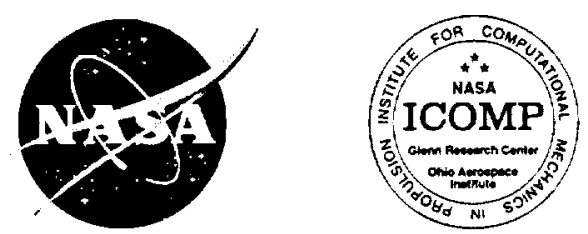

\section{Bypass Transitional Flow Calculations Using a Navier-Stokes Solver and Two-Equation Models}

William W. Liou

Western Michigan University, Kalamazoo, Michigan

Tsan-Hsing Shih

Institute for Computational Mechanics in Propulsion, Cleveland, Ohio

Prepared under Cooperative Agreement NCC3-520

National Aeronautics and

Space Administration

Glenn Research Center 
This report is a formal draft or working paper, intended to solicit comments and ideas from a technical peer group.

This report contains preliminary findings, subject to revision as analysis proceeds.

Trade names or manufacturers' names are used in this report for identification only. This usage does not constitute an official endorsement, either expressed or implied, by the National Aeronautics and Space Administration.

Available from

NASA Center for Aerospace Information

7121 Standard Drive

Hanover, MD 21076

Price Code: A03
National Technical Information Service 5285 Port Royal Road Springfield, VA 22100

Price Code: A03 


\title{
BYPASS TRANSITIONAL FLOW CALCULATIONS USING A NAVIER-STOKES SOLVER AND TWO-EQUATION MODELS
}

\author{
William W. Liou* \\ Mechanical and Aeronautical Engineering Department \\ Western Michigan University, Kalamazoo, Michigan \\ Tsan-Hsing Shih"* \\ Center for Modeling of Turbulence and Transition \\ ICOMP,NASA Lewis Research Center, Cleveland, Ohio
}

Bypass transitional flows over a flat plate were simulated using a Navier-Stokes solver and two-equation models. A new model for the bypass transition, which occurs in cases with high free stream turbulence intensity ( $\mathrm{TI}$ ), is described. The new transition model is developed by including an intermittency correction function to an existing two-equation turbulence model. The advantages of using Navier-Stokes equations, as opposed to boundary-layer equations, in bypass transition simulations are also illustrated. The results for two test flows over a flat plate with different levels of free stream turbulence intensity are reported. Comparisons with the experimental measurements show that the new model can capture very well both the onset and the length of bypass transition.

\section{Introduction}

Flows in turbomachinery component passages, such as compressors and turbines, are often transitional. With the high level of free stream turbulence in the turbomachinery passages, the transition in the boundary layer from a laminar flow to a turbulent flow is commonly referred to as bypass transition. Bypass transition occurs under the influence of free stream turbulence, in contrast to the natural transition which has its origion in the development of the Tollmien-Schlichting instability waves. The extent of the pre-transitional and transitional flow region on these blades can be very substantial at certain operating conditions and it is generally

\footnotetext{
-Assistant Professor. Member AIAA

* Technical Leader, CMOTT, Institute for Comutational Mechanics in Propulsion.
}

for these operating conditions that the present loss prediction methods fail. Therefore, a more accurate model for bypass transitional flow would improve loss predictions. Designers, equipped with better loss prediction schemes, can then fine-tune blade shapes to optimize boundary-layer losses for these operating conditions.

Concerning with the modeling of bypass transitional flows, Savill ${ }^{1}$ has reviewed an effort to assess existing two-equation turbulence models for the prediction of the bypass transition. The models were assessed for a few designated test cases, including flat plate boundary layers with various free stream TI and pressure gradients. The results submitted by the participants of that effort showed that none of the two-equation models tested could predict correctly either the onset or the length of the bypass transition region. Compared with the measurements, the predicted transition onsets were mostly too early and the length of transition region too short.

Computationally, predictions of bypass transitional flows were generally performed using a boundary-layer equation solver. This is a valid approach and is very cost effective. However, due to the parabolic nature of the boundary-layer equations, bypass transitional flow calculations using these equations have to begin at a location downstream of the leading edge of, for instance, a flat plate. Often, not all of the computational variables at the starting location can be defined based on the experimental data and one has to assume the profile distributions for those variables. For computations based on boundary-layer equations, the computational results depend significantly upon the starting locations and the starting flow profiles. Therefore, it is difficult to evaluate transition model in a fair and consistent manner based on the solutions of boundary-layer equations. To obtain more accurate simulations of bypass transitional flows, a Navier-Stokes solver is used in the 
present study. Moreover, the computational inlet is located upstream of the leading edge of the flat plate where the computational variables can be defined based on experimental data.

In this paper, we describe a new model for the prediction of bypass transition. Considering the intermittent nature of the transitional flow, we incorporate an intermittency function orrection to the eddy-viscosity predicted by a two-equation turbulence model. For the present study, a CMOTT variable- $C_{\mu}$ two-equation turbulence model ${ }^{2,3}$ was used. This is a variable $-C_{\mu}$ version of the Shih and Lumley two equation model ${ }^{4}$. Bypass transitional flows over a flat plate were investigated. They were designated as T3A and T3B by Savill ${ }^{1}$. The flows are selected to challenge models' capabilities to predict the effect of free stream TI ( $3 \%$ for T3A and $6 \%$ for T3B) on bypass transitional flows. The computational inlet is placed upstream of the leading edge of the plate, where there are sufficient measured data to clearly define the inlet flow quantities.

In the following sections, the turbulence models and the numerical platform used in this study are described. The results of flow calculations are also shown.

\section{Analysis}

\section{Mean Flow Equations}

The flow properties are decomposed into two parts: a mean value and a fluctuation with respect to the mean value. That is,

$$
\begin{aligned}
\hat{\rho} & =\rho+\rho^{\prime \prime} \\
\hat{u}_{i} & =U_{i}+u_{i}^{\prime} \\
\hat{p} & =p+p^{\prime \prime} \\
\hat{T} & =T+T^{\prime} \\
\hat{E} & =E+E^{\prime}
\end{aligned}
$$

where $\rho, p, T, E, U_{i}$ denote Reynolds-averaged density and pressure, mass-weighted-averaged temperature, total energy, and velocity, respectively. It is customary to use both the Reynolds average and the mass-weighted average in the decomposition process for compressible turbulent flows to simplify the final form of the mean flow equations. The governing equations for the mean flow may be obtained by substitution of flow properties in the form of eq.(1) into the Navier-Stokes equations followed by a Reynolds average of the equations. The mean flow equations become,

$$
\begin{gathered}
\rho, t+\left(\rho U_{i}\right)_{, i}=0 \\
\left(\rho U_{i}\right)_{, t}+\left(\rho U_{i} U_{j}+\tau_{i j}+p \delta_{i j}\right)_{, j}=0 \\
(\rho E)_{, t}+\left(\rho U_{i} E+p U_{i}+q T, i+\tau_{i j} U_{j}+q_{k, i}\right)_{, i}=0
\end{gathered}
$$

where

$$
\tau_{i j}=2\left(\mu+\mu_{t}\right) S_{i j}-\frac{2}{3} k \delta_{i j}
$$

$\mu$ denotes the mean molecular viscosity and $S_{i j}$ denotes the deviatoric part of the mean strain rate tensor, i.e.,

$$
S_{i j}=\frac{1}{2}\left(U_{i, j}+U_{j, i}\right)-\frac{1}{3} U_{k, k} \delta_{i j}
$$

The Reynolds stresses are modeled via the turbulent eddy viscosity, $\mu_{t}$. In all of the models used in this study, the turbulent eddy viscosity is determined by the turbulent kinetic energy, $k$, and the dissipation rate, $\varepsilon$.

$$
\mu_{t}=C_{\mu} f_{\mu} \rho \frac{k^{2}}{\varepsilon}
$$

$k$ and $\varepsilon$ are obtained from the solution of their respective model transport equations. $f_{\mu}$ is the wall damping function for the eddy-viscosity.

\section{Bypass Transition $\mathbf{k}-\epsilon$ Model}

A new transitional flow model is presented in the following. The model is developed based on the experimental observation that the flows in transition are highly intermittent. Locally, the flow is turbulent as the turbulent spots convect through. In between the passing of the turbulent spots, the flow relaxes to a disturbed laminar state. In this case, a measure of the fraction of time that the boundary layer is turbulent is the intermittency factor. Normally, the intermittent nature of the transitional flow was not accounted for in the development of turbulence models. Turbulence models were in general designed for flows in a fully turbulent state. To be able to use a turbulence model in the intermittent transitional flow region, we incorporate a weighting factor, $\gamma$, in the turbulent eddy viscosity , $\mu_{t}$, obtained from a base two-equation turbulence model, i.e.

$$
\mu_{t r}=\gamma \mu_{t}
$$

where $\mu_{t r}$ denotes transitional flow eddy-viscosity. The $\gamma$ function, or intermittency correction function, resembles the physical flow intermittency factor. Much like the intermittency factor that determines the fraction of time the flow is turbulent in the transition region, $\gamma$ determines the fraction of turbulent eddy-viscosity to be used in the transition region. Therefore, $\gamma$ should also vary monotonically through the transition region. Based on the same reasonings, Yang and Shih ${ }^{5}$ developed a $\gamma$ function using the shape factor of the boundary layer, i.e.

$$
\gamma=\gamma(H)=\gamma_{0}+\left(1-\gamma_{0}\right) \vec{H}^{n}
$$


where

$$
\bar{H}=\frac{H_{l}-H}{H_{l}-H_{t}}
$$

$H_{l}$ denote the value of the shape factor for the Blasius laminar boundary layer. $H_{t}$ is chosed to represent the shape factor for the turbulent boundary layer. $\gamma_{0}$ and $n$ are model constants. The model was found to work well for the bypass transition of flat plate boundary layer. The model uses the shape factor to characterize the state of the boundary layer. In a more complex geometry, such as a turbomachinery blade passage, the edge of the boundary layer that is needed to determine the displacement and momentum thickness is not welldefined. This sometime undermines the model's capability in transition predictions.

In the present study, the intermittency correction function $\gamma$ is defined in terms of the streamwise variation of the peak disturbance energy. The disturbance kinetic energy increases as the flow evolves from laminar to transitional state. Its local peak level also increases. Since the free stream turbulence influences the transition in the boundary layer mainly through the diffusion process, the higher the free stream turbulence, the faster the disturbance energy increases. Therefore, the disturbance energy level is an appropriate parameter to characterize the flow transitional region. The intermittency correction function we proposed in this study involves the peak disturbance energy level and the local free stream turbulence level.

$$
\begin{gathered}
\gamma=\gamma_{0}+\left(1-\gamma_{0}\right) f \\
f=\frac{k_{n}^{+}-k_{1}^{+}}{k_{2}^{+}-k_{1}^{+}}
\end{gathered}
$$

where

$$
\begin{gathered}
k_{n}^{+}=k_{n}^{+}(x)=\left.\max \left(k^{+}(x, y)\right)\right|_{x}-k_{e}^{+}(x) \\
k_{e}^{+}(x)=\frac{k_{e}(x)}{u_{r}^{2}(x)}
\end{gathered}
$$

$k_{e}$ and $u_{\tau}$ denote the local disturbance kinetic energy in the free stream and the local frictional velocity. The model coefficient $k_{1}^{+}$relates to the threshold for the formation of turbulent spots near the wall. Shih and Lumley ${ }^{4}$ have shown that turbulent energetic eddies reduce to Kolmogorov eddies near the wall, where $k^{+}=0.25$, and all the wall parameter are characterized by Kolmogorov microscales. An estimate for the spot generation threshold level in terms of $k^{+}$is thus set at 0.25 . It should be noted that the wall boundary condition for $k$ is also determined by the Kolmogorov behavior of near-wall turbulence in the base two-equation model. Therefore, the selection of the value of $k_{1}^{+}$is consistent with the base model. $k_{2}^{+}$is determined by examining fully developed turbulent boundary layer and its value is set at 4.5. The term $k_{2}^{+}-k_{1}^{+}$in $\mathrm{Eq} .(9)$ is used to normalize the term $k_{n}^{+}-k_{1}^{+}$, such that the transition progress variable, $f$, satisfies the equation $0 \leq f \leq 1$. The effect of the local free stream turbulence is accounted for in Eqs.(9) and (10). In Eq.(10), $k_{n}^{+}$represents the difference between the peak value and the free stream value of the $k^{+}$profile at a streamwise location, $x$. Eq.(10) allows the flow transition to proceed according to the internal peak level of the $k^{+}$profiles .

As was mentioned earlier, the base two-equation turbulence model was that used in Liou et al. ${ }^{2}$ and Yang et al. ${ }^{3}$. The model is described brietly in the following.

The model equations for $k$ and $\varepsilon$ are,

$$
\begin{aligned}
\rho k_{, t}+\rho U_{i} k_{, i} & =\left[\left(\mu+\mu_{t}\right) k_{, i}\right], i-\rho \widetilde{u_{i} u_{j}} U_{i, j}-\rho \varepsilon \\
\rho \varepsilon_{, t}+\rho U_{i} \varepsilon_{, i} & =\left[\left(\mu+\frac{\mu_{t}}{\sigma_{\varepsilon}}\right) \varepsilon_{, i}\right]_{, i}-C_{1} \frac{\varepsilon}{k} \rho \widetilde{u_{i} u_{j}} U_{i, j} \\
& -C_{2} f_{2} \rho \frac{\varepsilon^{2}}{k}+\nu \mu_{t} U_{i, j k} U_{i, j k}
\end{aligned}
$$

where

$$
\begin{gathered}
C_{1}=1.44, \quad C_{2}=1.92, \quad \sigma_{\varepsilon}=1.3 \\
f_{2}=1-0.22 \exp \left[-\left(\frac{R_{t}}{6}\right)^{2}\right], \quad R_{t}=\frac{k^{2}}{\nu \varepsilon} \\
C_{\mu}=\frac{1}{A_{0}+A_{s} U^{(*)} \frac{k}{\varepsilon}}
\end{gathered}
$$

where

$$
\begin{aligned}
U^{(\bullet)} & =\sqrt{S_{i j} S_{i j}+\bar{\Omega}_{i j} \bar{\Omega}_{i j}} \\
\bar{\Omega}_{i j} & =\bar{\Omega}_{i j}-2 \epsilon_{i j k} \omega_{k} \\
\bar{\Omega}_{i j} & =\Omega_{i j}-\epsilon_{i j k} \omega_{k}
\end{aligned}
$$

$\Omega_{i j}$ is the mean rotation rate viewed in a rotating reference frame with the angular velocity $\omega_{k}$. The parameter $A_{s}$ is determined by

$$
\begin{aligned}
& A_{s}=\sqrt{6} \cos \phi, \quad \phi=\frac{1}{3} \arccos (\sqrt{6} W) \\
& W=\frac{S_{i j} S_{j k} S_{k i}}{\bar{S}^{3}} \quad \bar{S}=\sqrt{S_{i j} S_{i j}}
\end{aligned}
$$

The damping function is defined by

$$
f_{\mu}=\left[1 .-\exp \left(-\left(a_{1} R_{k}+a_{3} R_{k}+a_{5} R_{k}\right)\right)\right]^{\frac{1}{2}}
$$

where

$$
a_{1}=1.7 \times 10^{-3}, a_{3}=10^{-9}, a_{5}=5 \times 10^{-10}
$$




$$
R_{k}=\frac{\rho \sqrt{k} y}{\mu}
$$

Note that the value of $C_{\mu}$ is bounded by 0.09 in the current application. The near-wall boundary conditions for the turbulent quantities are determined by examining the Kolmogorov behavior of near-wall turbulence proposed by Shih and Lumley ${ }^{4}$. They have shown that energetic eddies reduce to "Kolmogorov eddies" at a finite distance from the wall and all the wall parameters are characterized by Kolmogorov microscales. Therefore, an estimate can be obtained for the turbulent kinetic energy and its dissipation rate at the location where large eddies become Kolmogorov eddies by using both direct numerical simulation results and an asymptotic analysis of near wall turbulence. According to their analysis, this turbulent limit point is located at

$$
y_{\eta}=\frac{6 \nu}{u_{\tau}}
$$

At this limit point,

$$
k_{\eta}=0.25 u_{\tau}^{2} \text { and } \varepsilon_{\eta}=0.251 \frac{u_{\tau}^{4}}{\nu}
$$

In practice, the boundary conditions are enforced at the wall. With the application of eqns.(16) and (17), the turbulent time scale near a wall, similar to the velocity and length scales, is determined by the Kolmogorov time scale. Therefore, there is no unphysical singularity in the current model $\varepsilon$ equation.

The present intermittency correction function technique characterizes the transition progress by the variation of the disturbance energy. Therefore, the intermittency correction function does not necessarily correspond to the physical flow intermittency factor.

In the following, the numerical solution procedure is described.

\section{Numerical Solutions}

The Favre-averaged Navier-Stokes equations and the model transport equations have been solved numerically by using the COMTUR code developed by Huang and Coakley ${ }^{6}$. Briefly, it uses a line-by-line Gauss-Seidel algorithm and Roe's approximate Riemann solver. Yee's MINMOD TVD scheme was applied in all the computations. The mean and the turbulence equations are solved in a sequential manner. All the calculations have been carried out with the same initial and boundary conditions, including those for $k$ and $\varepsilon$. The computational inlet is located upstream of the leading edge of the plate. The inlet flow profiles are,

$$
U=U_{1}, V=0, k=k_{1}, \epsilon=\epsilon_{1}
$$

where the values of $U_{1}$ and $k_{1}$ are given by the measurement. The value of $\epsilon_{1}$ is obtained by examining the turbulence model transport equations for $k$ and $\epsilon$ at the free stream, i.e.,

$$
\begin{aligned}
& U_{1} \frac{d k_{e}}{d x}=-\epsilon_{e} \\
& U_{1} \frac{d \epsilon_{e}}{d x}=-C_{2} \frac{\epsilon_{e}^{2}}{k_{e}}
\end{aligned}
$$

The value for $\epsilon_{1}$ is determined such that, with $k_{1}$ and $\epsilon_{1}$ as initial values, the solution for $k_{e}$ obtained from Eq.(19) agrees with the measured data.

The computational domain was covered with orthogonal surface-fitted meshes, with grid clustering near the leading edge and the wall. Several different meshes were used to ensure grid-independence, by varying both the number of grid nodes and the grid clustering. The results of the grid independent study are described in the next section. The results obtained by using the Launder and Sharma (LS) turbulence model ${ }^{7}$, which is regarded as one of the models that can predict well bypass transitional flows, are also shown for comparison.

\section{Results and Discussions}

In this section, the simulation results for T3A ( $3 \%$ TI and zero pressure gradient) and T3B (6\% TI and zeor pressure gradient) are reported.

- Fully Laminar and Turbulent Boundary-Layer Flows

Since the transitional boundary-layer flow over a flat plate consists of a region of laminar flow before the flow become transitional, it is essential that the numerical solver be able to calculate laminar boundary-layer flows. To validate the Navier-Stokes solver, the laminar boundary layer on a flat plate was first calculated. The flow conditions correspond to that of the T3B case. In this calculation, the turbulence model equations were not solved and the eddy-viscosity was set to zero. Therefore, the computational results represent the numerical solution of the Navier-Stokes equations for a laminar boundary-layer flow over a flat plate. The calculated and the theoretical skin friction distributions are compared in Fig.(1). The good agreement between the analytical curve and the computational results shows that the solver can faithfully describe fully laminar boundary-layer flows. A fiat plate turbulent boundary layer was then calculated using the LS model. For a fully turbulent flow, the model transport equations for $k$ and $\epsilon$ were solved and the resulting eddyviscosity was used in the mean flow calculations. The computed skin friction coefficient and the Van Driest 
II correlation for skin friction for turbulent boundarylayer flows are included in Fig.(1). For a fully developed turbulent boundary layer, the results show that the LS model slightly under-predicts the skin friction coefficient, which has been observed in many other calculations of such flows. The fully laminar and fully turbulent flow calculations results suggest that the numerical solver is accurate and the LS model is correctly implemented.

\section{- Free Stream Turbulence Decay}

As was mentioned earlier, uniform profiles for the mean and the turbulence quantities were used at the computational inlet. The levels of the turbulent kinetic energy and the rate of dissipation at the inlet were set such that the decay of the turbulent kinetic energy, according to Eq.(19), would agree with the measured data. It has generally been observed in experiments that the location of the onset of transition moves upstream as the turbulence level (TI) in the free stream increases. Therefore, it is important in a bypass transition simulation that the computed decay of free stream turbulence matches with that of the measurement. Fig.(2) shows a comparison of the computed streamwise distribution of the free stream turbulent kinetic energy with the measurement. The computed results are the solution of the Reynolds-averaged Navier-Stokes equations and the LS model. There is a good agreement between the computed and the measured distributions. In fact, it is found in the gridindependency studies that the free stream turbulent kinetic energy distribution is rather insensitive to the grid point variation.

\section{- Computational Inlet}

Fig.(3) shows two distributions of calculated and the measured shape factors using the same grid of $120 \times 120$ and the LS model. The computational inlet was located at the leading edge. The distance from the leading edge to the first grid point downstream, $d x_{0}$, are $10^{-3} \mathrm{~m}$ and $2 \times 10^{-5} \mathrm{~m}$, respectively. The inlet turbulent kinetic energy and the rate of dissipation were determined by Eq.(19). The inlet velocity profiles were taken from the Blasius solutions, i.e.,

$$
U=U_{\text {Blasius }}, V=0 .
$$

The large changes in the shape factor near the leading edge in the case with a small $d x_{0}$ indicates that there is an adjustment of the flow from the given inlet profiles to the Navier-Stokes solutions. It seems that, for the case with a larger $d x_{0}$, the flow self-adjustment has not completed before the predicted onset of transition. Therefore, with the computational inlet placed at the leading edge, it is possible that the computed flow is not entirely free of the error introduced in the numerical inlet conditions before the transition onset and the prediction of transitions can be inappropriately affected. Consequently, for numerical simulations of the bypass transitional flows over a flat plate, it is more appropriate to place the computational inlet at the upstream of the leading edge, where the experiment can provide data necessary for the determination of numerical inlet conditions. Fig.(4) shows the comparison of the calculated skin friction coefficient with computational inlet located at upstream $\left(x_{0}=-0.017 \mathrm{~m}\right)$ of and at the leading edge $\left(x_{0}=0 \mathrm{~m}\right)$, respectively. The grid atop the flat plate is the same for both cases, which is $120 \times 120$, and $d x_{0}=2 \times 10^{-5} \mathrm{~m}$. The results show that there is a significant diference in the predicted location of transition onset and transition length. Therefore, it is necessary for the computational inlet to be located upstream of the leading edge of the flat plate.

\section{- Grid Sensitivity}

Orthogonal H-type grids are used in the present calculations. A typical grid of $160 \times 120$ is shown in Fig. (5).

In the cross-stream direction, the value of $y^{+}$for the first grid point away from the wall was set to be less than 0.1 in the fully turbulent flow region. In the streamwise direction, the grid density is high near the leading edge to resolve the large local flow gradients.

Fig.(6) shows the results of the grid independent studies by continuously refining the grid in the streamwise direction. The grids are $135 \times 120,215 \times 120,255 \times$ $120,285 \times 120,335 \times 120$. There is no significant difference in the skin friction coefficient, which is very sensitive to grid density, among those obtained from the $255 \times 120,285 \times 120$, and the $335 \times 120$ meshes.

Fig.(7) shows the calculated skin friction coefficient using grids of $255 \times 120$ and $255 \times 160$. The results show little difference. These results indicate that the $255 \times 120$ grid can provide a solution of a fairly high level of grid independency.

\section{- Model Comparisons : T3A}

The free stream turbulence intensity is $3 \%$ for case T3A. The computational mesh is $255 \times 120$. The inlet conditions and the mesh for the present model are identical to that for the LS model. The Fig.(8) shows the comparison of computed and measured ${ }^{1}$ skin friction coefficients, $C_{f}$, as functions of $R e_{x}$. The present model predicts very well for both the onset and the length of the transition region. The current model's prediction of the variation of $C_{f}$ through the transitional region also agree well with the measurement. The peak value of $C_{f}$, which occurs near the end of the transition zone, is also well predicted, indicating that the current model 
can predict the location of the maximum momentum (or heat) transfer.

The calculated and measured streamwise variations of the shape factor are shown in Fig.(9). The result from the LS model is also shown for comparison.

\section{- Model Comparisons : T3B}

For the T3B case, the free stream turbulence is about $6 \%$. We have used a computational mesh of $255 \times 120$ for both models. Again, the inlet conditions are the same for both the present model and the LS model. A comparison of the calculated and the measured streamwise variation of $C_{f}$ is shown in Fig.(10). The transition onset is predicted well by the present model. Compared with the data points available, the predicted length of the transition region appears to be somewhat shorter. The difference between the predicted maximum value of $C_{f}$ and the maximum value of $C_{f}$ of the available data is about $4 \%$, which falls within the experimental margin of error for such a measurement.

Fig.(11) shows the streamwise variation of the shape factors. The LS model predicts an earlier drop off than the measurement. The present model, on the other hand, predict a delayed occurrence of such a decrease of the shape factor.

In Fig.(12), the calculated distributions of the disturbance kinetic energy, $k$, along the direction normal to plate at six strearnwise locations are shown. The normal distances $y$ for the individual streamwise locations are nondimensionalized by their respective boundary layer thickness, $\delta$, and the $k$ are nondimensionalized by the free stream velocity at the inlet. Note that the present model uses the local peak value of $k$ to characterize the transition progress variable, $f$. At $R e_{x}=10^{4}$, where the calculated flow is laminar, $k$ varies almost linearly within the boundary layer and there is no internal peak value. At later locations, an internal peak begins to appear in the $k$ profile. The peak value increases as the flow goes through the transition process. At $R e_{x}=10^{5}$, the peak value of $k$ appears to be leveling off and begin to decrease. According to the variation of peak value of $k$, the model is predicting a gradually increasing turbulence intensity as the flow develop in the transition region. The turbulence intensity reaches a maximum level at about $R e_{x}=10^{5}$, which roughly corresponds to the calculated maximum $C_{f}$. The results shows that the local peak value of $k$ is an appropri- ate parameter for characterizing the bypass transition process.

\section{Summary}

A new model for bypass transitional flows has been described. The model is developed based on the observation that the transitional boundary layers are high intermittent and, accordingly, an intermittency correction function is incorporated in the turbulent eddyviscosity. The model has been tested for bypass transitional flat plate boundary layers with different levels of turbulence intensity in the free stream using a NavierStokes equations solver. The results show that the present model can capture very well the effects of free stream turbulence on bypass transition. It should be noted that the Launder and Sharma's turbulence model is not a dedicated bypass transition model. Therefore, its results shown here for the bypass transition cases should be viewed accordingly.

\section{References}

1 Savill, A.M., "A synthesis of T3 test case predictions", Numerical Simulation of Unsteady Flows and Transition to Turbulence, Edt. Pironneau, $O$. et al., 1992.

2 Liou, W.W. and Shih, T.H., "Transonic turbulent flow predictions with new two-equation turbulence models," AIAA-95-1805.

3 Yang, Z., Georgiadis, N., Zhu, J., and Shih, T.-H., "Calculations of inlet/nozzle flows using a new $k-\varepsilon$ model," AIAA paper 95-2761 (1995).

4 Shih, T. H. and Lumley, J. L., "Kolmogorov behavior of near-wall turbulence and its application in turbulence modeling," Comp. Fluid Dyn., 1, 43-56 (1993).

5 Yang, Z. and Shih, T.H., "A k- $\epsilon$ model for turbulent and transitional boundary layers," Proceedings of Near-Wall Turbulent Flows, Edt. R.M.C. SO, C.G. Speziale and B.E. Launder, Elsevier 1993.

${ }^{6}$ Huang, P. G. and Coakley, T. J., "An implicit Navier-Stokes code for turbulent flow modeling," AIAA paper 92-0547 (1992).

7 Launder, B.E. and Sharma, B.I., "Application of the energy-dissipation model of turbulence to the calculation of flow near a spinning disc, Letters in Heat and Mass Transfer, 1, pp.131-139 (1974). 


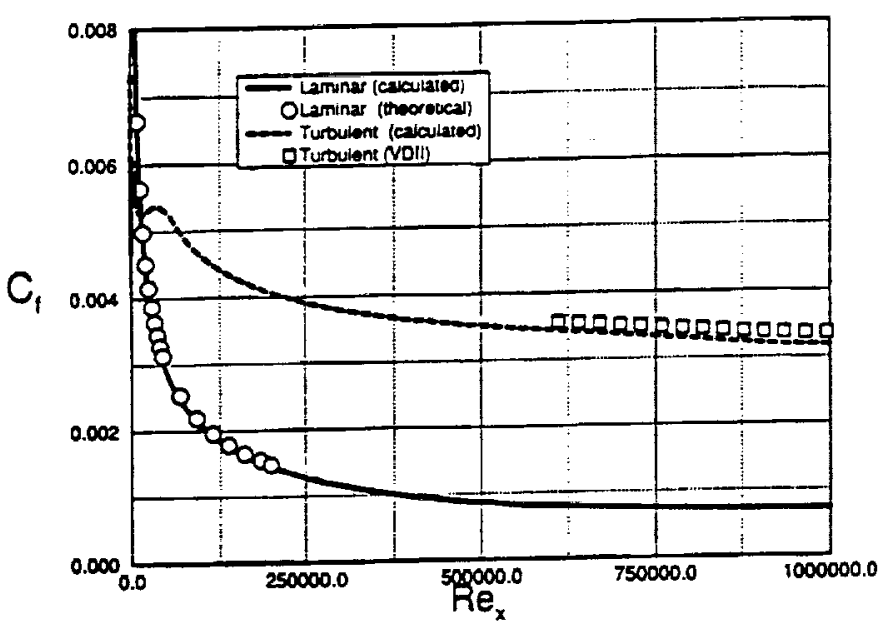

Fig.(1) Skin friction coefficient for boundary layers.

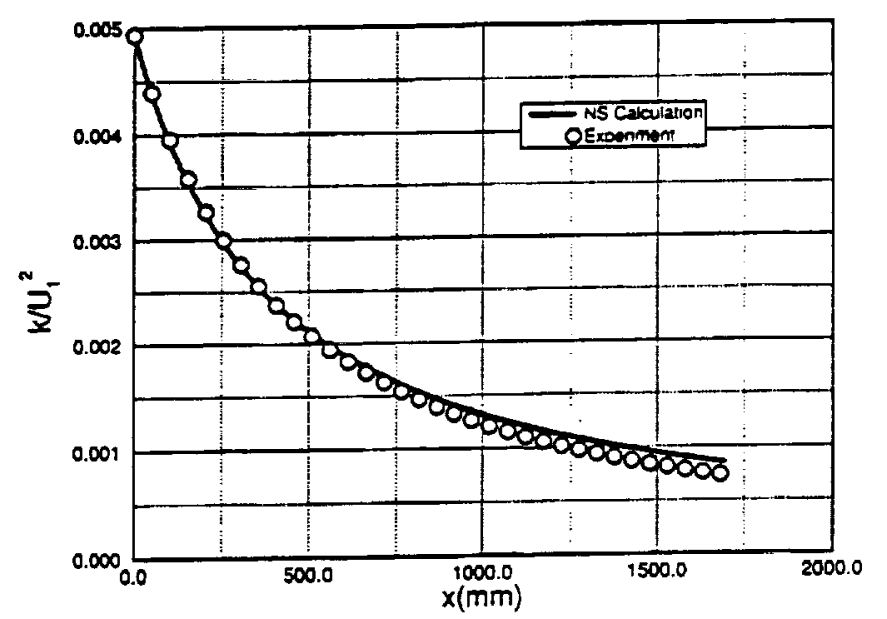

Fig.(2) Free stream turbulent kinetic energy distributions.

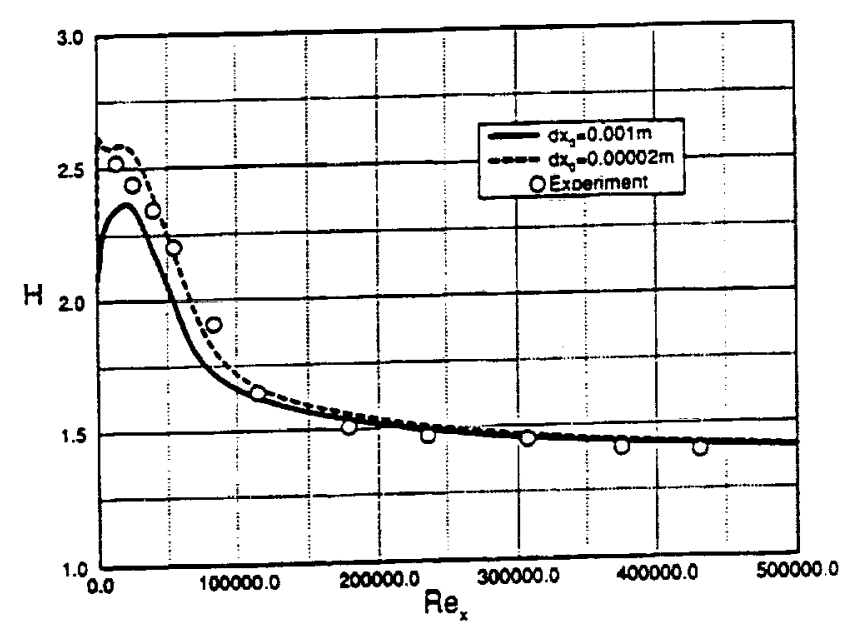

Fig.(3) Shape factor distributions.

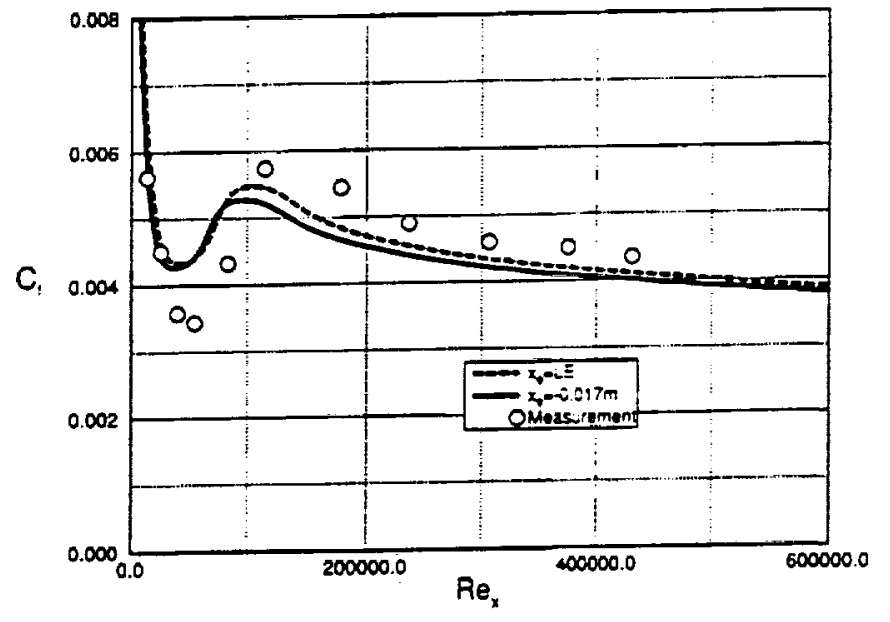

Fig.(4) Comparisons of skin friction coefficient.

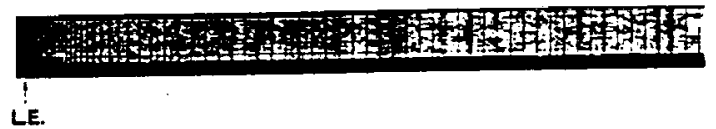

Fig.(5) A typical computational grid.

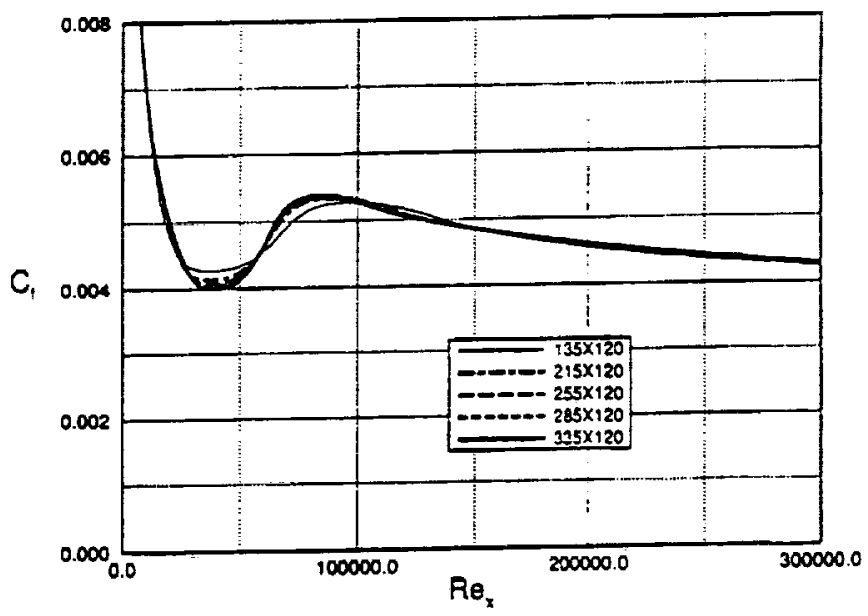

Fig.(6) Grid independent study with grid refinement in the streamwise direction. 


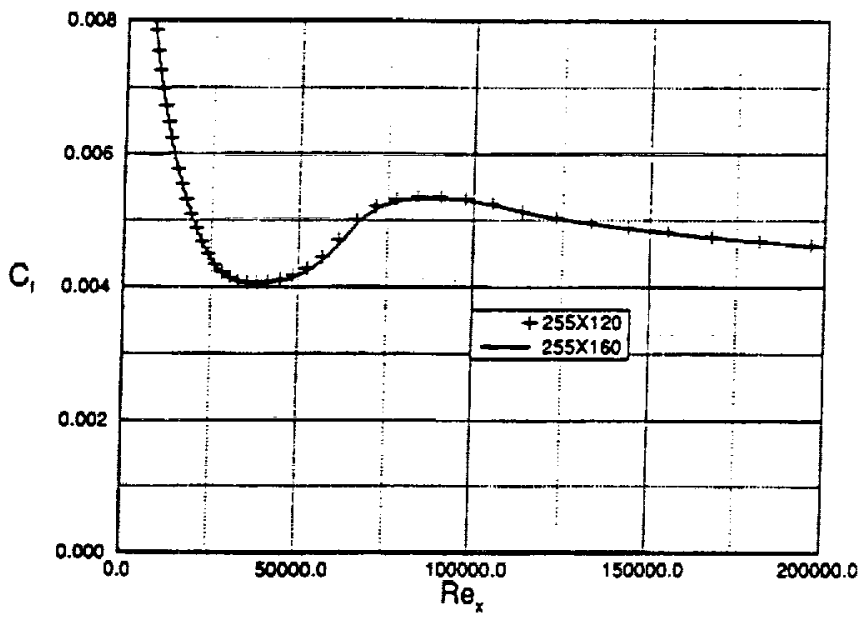

Fig.(7) Grid independent study with grid refinement in the direction normal to the plate.

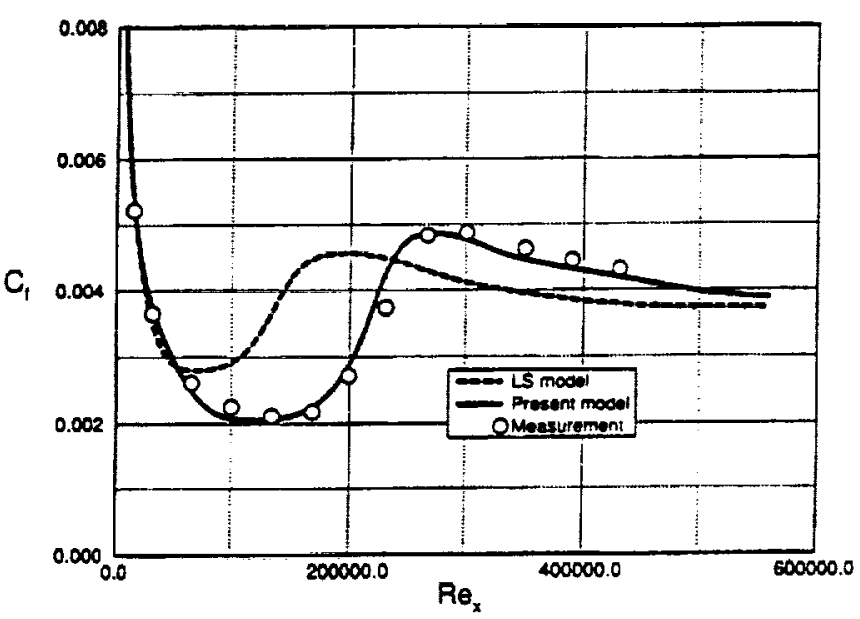

Fig. (8) Comparison of skin friction coefficients.T3A.

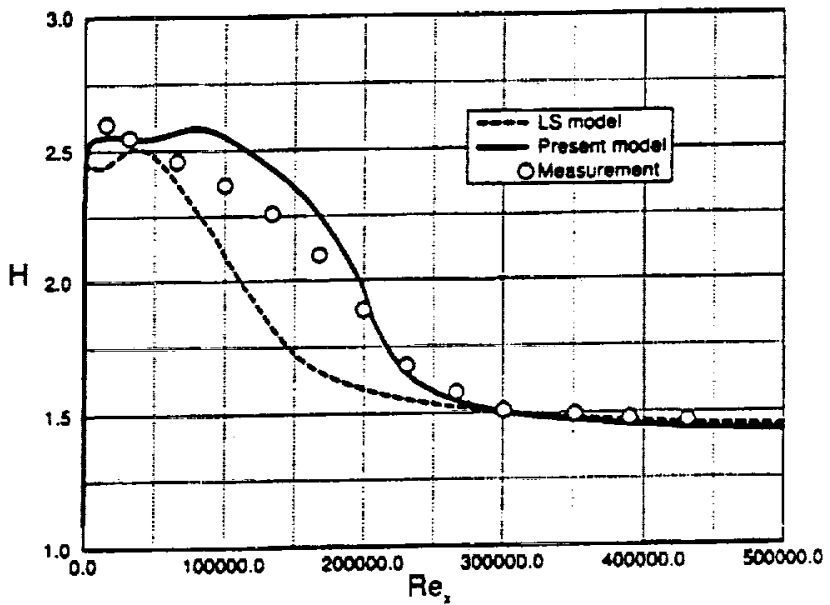

Fig.(9) Comparison of shape factor distributions.T3A.

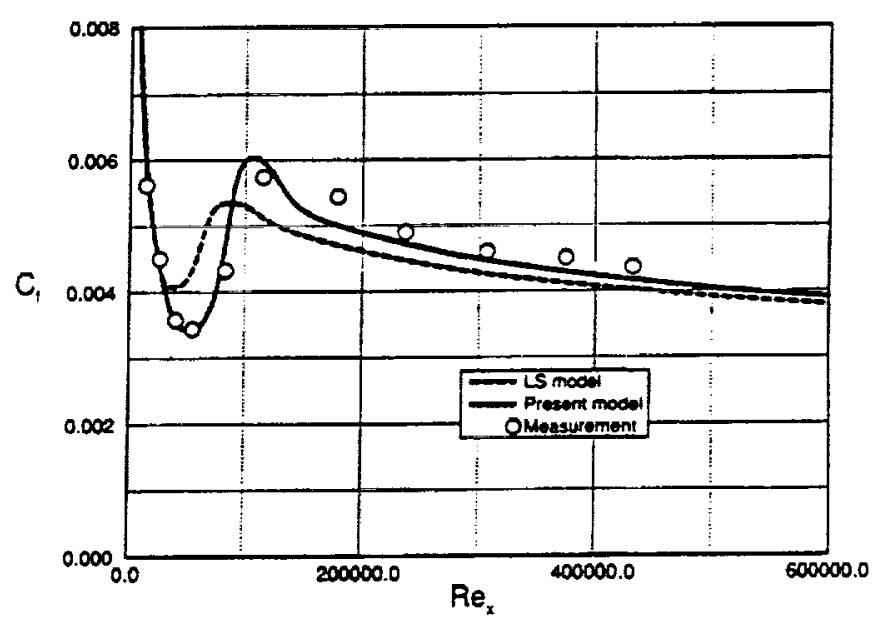

Fig.(10) Comparison of skin friciton coefficients. T3B.

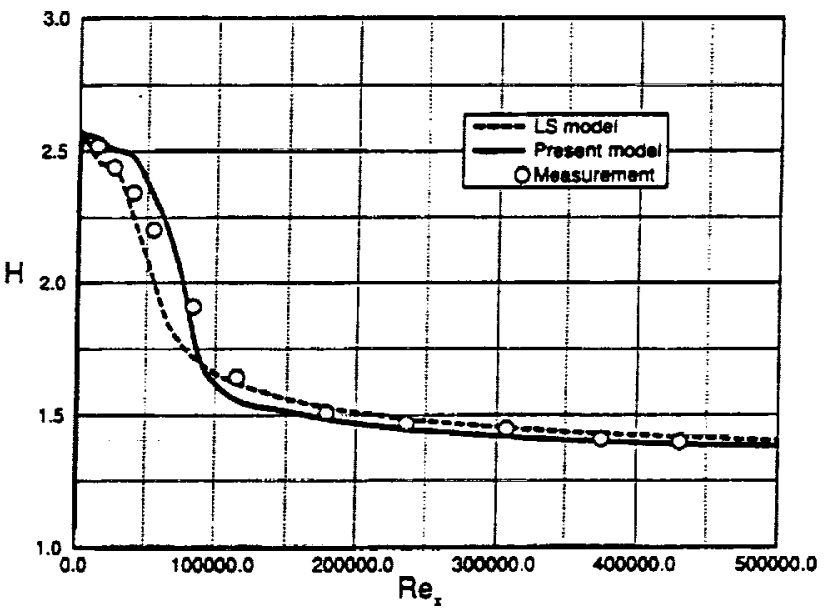

Fig.(11) Comparison of shape factor distributions.T3B.

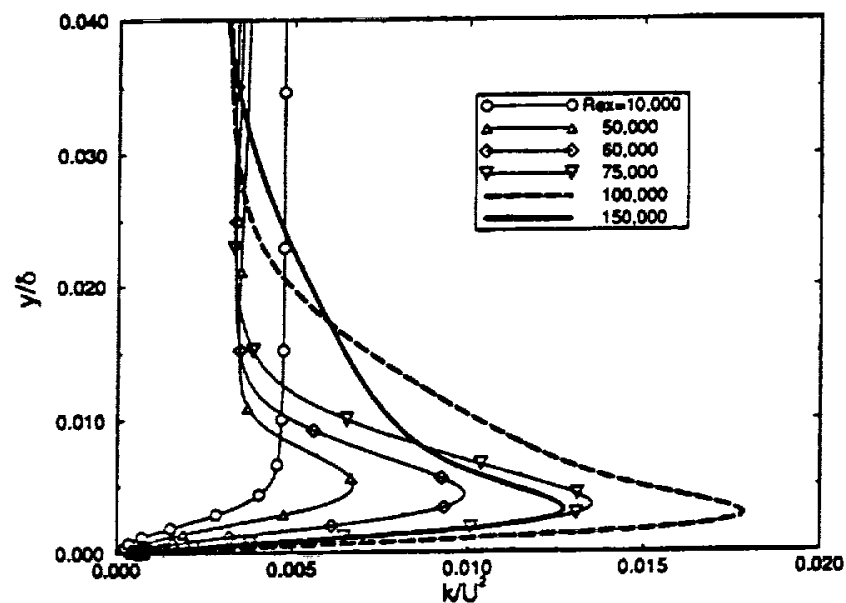

Fig.(12) Disturbance kinetic energy distrubutions in the direction normal to the fiat plate at different streamwise locations. T3B 


\begin{tabular}{|c|c|c|c|c|}
\hline \multicolumn{3}{|c|}{ REPORT DOCUMENTATION PAGE } & & $\begin{array}{l}\text { Form Approved } \\
\text { OMB No. 0704-0188 }\end{array}$ \\
\hline \multicolumn{5}{|c|}{ 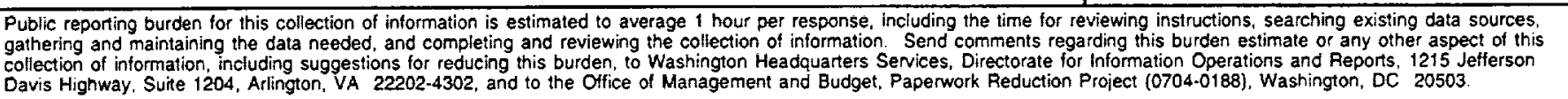 } \\
\hline 1. AGENCY USE ONLY (Leave blank) & $\begin{array}{r}\text { 2. REPORT DATE } \\
\text { April } 2000\end{array}$ & \multicolumn{3}{|c|}{$\begin{array}{l}\text { 3. REPORT TYPE AND DATES COVERED } \\
\text { Contractor Report }\end{array}$} \\
\hline \multicolumn{3}{|c|}{$\begin{array}{l}\text { 4. TITLE AND SUBTITLE } \\
\text { Bypass Transitional Flow Calculations Using a Navier-Stokes Solver and } \\
\text { Two-Equation Models }\end{array}$} & \multirow{2}{*}{\multicolumn{2}{|c|}{$\begin{array}{l}\text { 5. FUNDING NUMBERS } \\
\text { WU-522-31-23-00 } \\
\text { NCC3-520 }\end{array}$}} \\
\hline \multicolumn{3}{|c|}{$\begin{array}{l}\text { 6. AUTHOR(S) } \\
\text { William W. Liou and Tsan-Hsing Shih }\end{array}$} & & \\
\hline \multicolumn{3}{|c|}{$\begin{array}{l}\text { 7. PERFORMING ORGANIZATION NAME(S) AND ADDRESS(ES) } \\
\text { Institute for Computational Mechanics in Propulsion } \\
22800 \text { Cedar Point Road } \\
\text { Cleveland, Ohio } 44142\end{array}$} & $\begin{array}{l}\text { 8. PEI } \\
\text { RE }\end{array}$ & $\begin{array}{l}\text { ORMING ORGANIZATION } \\
\text { ORT NUMBER } \\
12162\end{array}$ \\
\hline \multicolumn{3}{|c|}{$\begin{array}{l}\text { 9. SPONSORING/MONITORING AGENCY NAME(S) AND ADDRESS(ES) } \\
\text { National Aeronautics and Space Administration } \\
\text { John H. Glenn Research Center at Lewis Field } \\
\text { Cleveland, Ohio 44135-3191 }\end{array}$} & \multicolumn{2}{|c|}{$\begin{array}{l}\text { 10. SPONSORING/MONITORING } \\
\text { AGENCY REPORT NUMBER } \\
\text { NASA CR-2000-209923 } \\
\text { ICOMP-2000-03 }\end{array}$} \\
\hline \multicolumn{5}{|c|}{$\begin{array}{l}\text { William W. Liou, Mechanical and Aeronautical Engineering Department, Western Michigan University, Kalamazoo, } \\
\text { Michigan 49008; and Tsan-Hsing Shih, Center of Modeling of Turbulence and Transition, Institute for Computational } \\
\text { Mechanics in Propulsion, Cleveland, Ohio 44135. Project Manager, L.A. Povinelli, Research and Technology Directorate, } \\
\text { organization code 5000, (216) 433-5818. }\end{array}$} \\
\hline \multicolumn{3}{|c|}{ 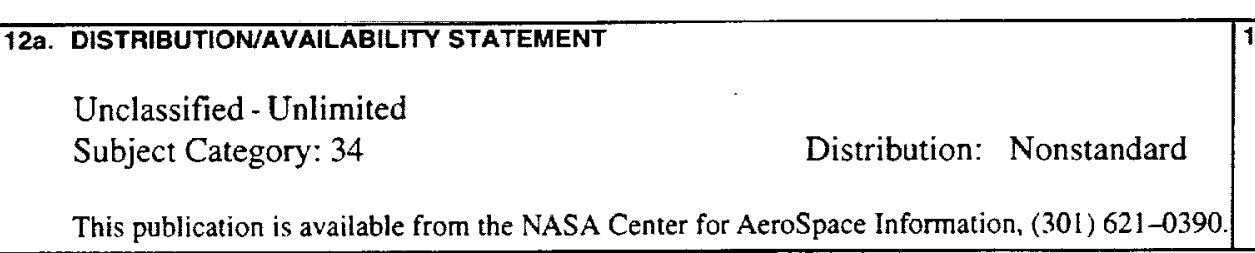 } & \multicolumn{2}{|c|}{ 12b. DISTRIBUTION CODE } \\
\hline \multicolumn{5}{|l|}{$\begin{array}{l}\text { lence model. The ad } \\
\text { transition simulation } \\
\text { turbulence intensity } \\
\text { very well both the on }\end{array}$} \\
\hline & & $\begin{array}{c}\text { 15. NUMBER OF PAGES } \\
14\end{array}$ \\
\hline \multicolumn{4}{|c|}{ Turbulence modeling; Transition; Navier-Stokes equations; Compressible flows } & 16. PRICE CODE \\
\hline $\begin{array}{l}\text { 17. SECURITY CLASSIFICATION } \\
\text { OF REPORT }\end{array}$ & $\begin{array}{l}\text { 18. SECURITY CLASSIFICATION } \\
\text { OF THIS PAGE }\end{array}$ & $\begin{array}{l}\text { 19. SECURITY CLASSIFICAT } \\
\text { OF ABSTRACT }\end{array}$ & TION & \begin{tabular}{|c|} 
AO3 \\
20. LIMITATION OF ABSTRACT
\end{tabular} \\
\hline Unclassified & Unclassified & Unclassified & & \\
\hline NSN 7540-01-280-5500 & & & & $\begin{array}{l}\text { ndard Form } 298 \text { (Rev. 2-89) } \\
\text { scribed by ANSI Std. Z39-18 } \\
-102\end{array}$ \\
\hline
\end{tabular}

